Published by Al-Nahrain College of Medicine P-ISSN 1681-6579

E-ISSN 2224-4719

Email: iraqijms@colmed-alnahrain.edu.iq

http://www.colmed-alnahrain.edu.iq

http://www.iraqijms.net

Iraqi JMS 2019; Vol. 17(1)

\title{
Association of Human Herpes Virus 6A Infection in Endometrial Epithelial Cells with Miscarriage
}

\author{
Huda S. Dosh ${ }^{1}$ BSC, Ahmed S. Abdulamir ${ }^{2}$ PhD, Sahar H. Abdul-Razzaq ${ }^{3}$ FACMS-OG, CABOG, DGO \\ ${ }^{1}$ Dept. of Medical Laboratory Techniques, Ministry of Health Directorate of Wasit, General Al-Suwayrah Hospital \\ ${ }^{2}$ Dept. of Microbiology, ${ }^{3}$ Dept. of Gynecology, College of Medicine, Al-Nahrain University, Baghdad, Iraq
}

\begin{abstract}
Background The microbial infections are major cause in abortion, of which viruses appear to be the most frequently involved pathogens. Human Herpes Virus-6 (HHV-6) has been implicated in cases of poor pregnancy outcome.

Objective Detection and quantification of HHV-6 viral load along with titer of IgM and IgG in endometrial epithelial cells of women with unexplained miscarriage (cases group) compared to the decidual endometrial tissue in women with full term conception (the control group).

Methods A total of 90 samples, 45 were taken by curettage from miscarriage women at first and second trimesters of pregnancy and 45 were taken from women with full term pregnancy during caesarian operation. HHV-6 DNA was extracted from uterus lining tissue samples, and then it was detected and measured by real time qPCR; in addition, $3 \mathrm{ml}$ of blood were collected from each subject for detection of HHV-6 IgM and IgG antibodies.

Results HHV-6 DNA was detected in uterus lining tissue of $20 \%$ of abortion and $22.22 \%$ of controls ( $P$ value $=0.79$ ). The median viral load of HHV-6 per 106 of uterine cells in abortion group was 15, while for control group was $13(\mathrm{P}=0.54)$. HHV-6 load increased with increased number of previous abortions, and it increased with presence of recurrent abortion history. It showed significant differences in the median of HHV-6 DNA load between recurrent abortion and non-recurrent abortion groups ( $P$ value $=0.033$ ). Positive anti-HHV-6 IgM serum antibodies in HHV-6 DNA detected and no-detected subjects were 0\%, and 9.85\% respectively; the positive anti-HHV-6 IgG serum antibodies in detected HHV-6 DNA were 100\%, while 83\% in HHV-6 DNA nondetected subjects. The combination of positive/negative results of the anti-HHV-6 IgG and IgM serum antibodies in HHV-6 DNA detected versus non-detected group showed $100 \%$ of HHV-6 DNA detected were positive for IgG and negative for IgM, versus $73 \%$ in non-detected group.

Conclusion HHV-6 might associated with unexplained miscarriage. HHV-6 infection might increase with increased number of previous abortions, and increased with presence of recurrent abortion history.

Human Herpes Virus 6A, Miscarriage

Keywords

Citation

Dosh HS, Abdulamir AS, Abdul-Razzaq SH. Association of Human Herpes Virus 6A infection in endometrial epithelial cells with miscarriage. Iraqi JMS. 2019; 17(1): 57-65. doi: 10.22578/IJMS.17.1.9
\end{abstract}

List of abbreviations: HHV- 6 = Human herpesvirus- 6 , IgG = Immunoglobulin G, IgM = Immunoglobulin M

\section{Introduction}

$\mathrm{H}$ uman herpesvirus-6 (HHV-6) is an ubiquitous beta-herpes virus commonly distributed in the general population. The primary infection usually occurs in the early years of life and remains latent in the host for the lifelong period (1). HHV-6 has been recognized as the etiological agent of Rosella infantum. HHV-6 includes two variants, HHV-6A and HHV-6B. Recently, two major subspecies have distinguished on the basis of biological, immunological, and genetic divergence ${ }^{(2)}$. Both variants infect mainly T-cells. The majority of population is infected by HHV6-B by 2 years of age and HHV-6A infection frequently occurs later in life. HHV-6A and B have varied tropism $(1,3)$. Evidence suggests that HHV-6 can infect and replicate in human genital tract. HHV-6 DNA has 
been detected in genital tract secretion from pregnant and non-pregnant women. Numerous studies have reported the high viral shedding in pregnant women ${ }^{(4-6)}$.

Clinical manifestation of HHV-6 have not been clearly defined, especially in adult patients and the role of HHV- 6 in human diseases remains to be completely explained. Numbers of studies trying to find and evaluate the role of betaherpes viruses' infection in the development of various chronic diseases, but still there is no final answer for this question. It may be due to their ubiquitous nature and different mechanisms to interference with the host that these viruses are using $(1,5,7)$.

Miscarriage is the spontaneous loss of pregnancy. There are two types of miscarriage before 12 weeks called early miscarriage and from 12 to 24 weeks called late miscarriage ${ }^{(8)}$. Pregnancy loss has been attributed to several factors involved in human reproduction. The causes of abortions in many cases are still unknown. However microbial infections have been characterized as a major cause in abortion, of which viruses appear to be the most frequently involved pathogens $(9,10)$.

HHV- 6 has been implicated in cases of poor pregnancy outcome due to ability of virus to disrupt endometrium epithelial cells function that lead to inhibit the creation of appropriate uterine environment for implantation and fetal growth that lead to infertility and miscarriage (11).

In 2016, HHV-6A was found in endometrial biopsies from primary unexplained infertile women, but not in control women. On the contrary, HHV-6B was not found in endometrial biopsies of both groups ${ }^{(12)}$. In another studies, the diagnosis of HHV-6A infection in pregnant women, and the detection of HHV-6A DNA in all of fetal tissue, umbilical cord blood samples of healthy newborns, and the placental tissue suggest the possible role of the virus in miscarriage at 24 weeks of gestation $(7,13,14)$.

Several diagnostic methods used for viral detection among them quantitative real time polymerase chain reaction (real-time $\mathrm{qPCR}$ ) in endometrial epithelial cells samples which is considered the method of choice ${ }^{(12)}$.

This study aimed to investigate the association of HHV- 6 with the unexplained miscarriage of women by doing the following:

1. Detection of HHV-6 in endometrial epithelial cells of women with unexplained miscarriage (cases group) compared to the decidual endometrial tissue in women with full term conception, (the control group).

2. Serological evaluation of HHV-6 in the serum of women with unexplained miscarriage compared to control group, namely the in women with full term conception.

Also aimed to evaluate the feasibility of using HHV- 6 serology as a cheap and simple indicator for underlying HHV-6 infection of endometrium and assess the odd ratio of using HHV-6 serology as a possible predictor for unexplained miscarriage.

\section{Methods}

The current study is case control study conducted in the period from November 2017 to September 2018. A total of 90 subjects were involved in this study, 45 women miscarriage at first and second trimesters of pregnancy and 45 women with full term pregnancy who underwent caesarian operation in Al-Imamein Al-Kadhimein Medical City. A consent letter was signed by each volunteer, and the study was approved by the ethical committees of the Ministry of Health of Iraq and of Al-Nahrain Collage of Medicine.

\section{Inclusion criteria}

Women with age ranged from 20 to 40 years old with unexplained miscarriage till 24 weeks of pregnancy were taken as cases, while women with full-term pregnancy during the conduction of cesarean operation have more than one successful pregnancy were taken as controls.

\section{Exclusion criteria}

Women with other causes of miscarriage such as endocrine disorder (diabetes mellitus, thyroid disorder), anatomical causes acquired or congenital thrombophilia and other infection 
causes miscarriage such as toxoplasmosis, cytomegalovirus infection, rubella and herpes simplex-2.

\section{HHV-6 DNA detection and quantification}

Accordingly, 90 biopsies of uterus-lining tissues in which HHV-6 is suspected to be found, were collected. The tissue lining uterus at the first trimester of pregnancy was routinely taken by curettage from 45 women with unexplained miscarriage; the endometrial tissue was identified from placental tissue by the consultant gynecologist of this study. In addition, the decidual tissue, the uterus lining tissue at full term gestation was taken from 45 women with full-term pregnancy during the conduction of cesarean operation. Tissue samples of approximately 2 grams were cut and put in Eppendorf tubes and stored at $-20{ }^{\circ} \mathrm{C}$ till DNA extraction. HHV-6 DNA was detected and measured by real time qPCR. Reaction volume $=25 \mu \mathrm{l}(15 \mu \mathrm{l}$ reaction $\operatorname{mix}+10 \mu \mathrm{l}$ of extracted DNA). The thermal protocol used was specified by the kit manufacturer (Sacace/ Italy), namely HHV-6 Real-TM Quant.

\section{Serology of HHV-6 IgG and IgM antibodies}

In addition, $3 \mathrm{ml}$ of blood were collected from each subject and put in a plane tube and then were subjected to centrifugation for serum separation. Serum samples were subjected for Enzyme Linked Immune Sorbent Assay (ELISA) technique for detection of HHV-6 IgM and IgG. The HHV-6 IgM and IgG ELISA kit (VIDIA/Czechoslovakia) for the semiquantitative measurement of $\lg M$ and $\lg G$ antibodies titer to HHV-6 in human serum. The strips are coated with native HHV- 6 antigen. If the specimens contain IgM or IgG antibodies to HHV-6, it will bind to the immobilized antigens to form immobilized immune complexes. The immune complexes are recognized by animal anti- human IgM or IgG antibodies with enzyme. The enzymatic reaction was revealed with chromogen substrate to produce a yellow color indicating the amount of $\mathrm{HH}-6 \mathrm{IgM}$ and $\operatorname{lgG}$ antibodies present in the specimens.

\section{Statistical analysis}

For the nominal qualitative data, Chi square and Fisher exact tests were used for association measurement. For quantitative data mean or median difference measuring tests were used. For parametric data, student t-test was used, while for non-parametric data Mann-Whitney test was used. Odds ratio is used to study the to compare the relative odds of occurrence of the outcome. In addition, $\mathrm{P}$ value was used to test the null hypothesis and determine the significance of testing. $P$ value less than 0.05 was indicative for a significant result.

\section{Results}

The mean of age of abortion group was 29.17 and of control group was 28.22 range from 20 to 40 years old. This study showed that uterus lining tissue of 9 out of 45 abortion (20\%) and 10 out of 45 control group (22.22\%) harbored HHV6 in by using Real Time PCR. However, the rate of HHV-6 detection was not significantly different $(P$ value $=0.79)$ between abortion and control groups (Table 1 ).

Table 1. Detection rate of HHV-6 in uterus lining tissue between abortion and controls groups

\begin{tabular}{cccc}
\hline & Detected & Non-detected & Total \\
\hline \multirow{2}{*}{ Abortion } & 9 & 36 & 45 \\
& $20.0 \%$ & $80.0 \%$ & $100 \%$ \\
Control & 10 & 35 & 45 \\
& $22.22 \%$ & $77.78 \%$ & $100 \%$ \\
\hline
\end{tabular}

Chi square $p$ value $=0.79$ 
This study showed a higher frequency of recurrent abortions in HHV-6 DNA detected group than HHV-6 DNA non-detected group but it did not reach the statistical significance level
( $P$ value $=0.14)$. It was $15.79 \%$ from HHV-6 DNA detected group versus only $5.63 \%$ of HHV-6 DNA non-detected group with recurrent abortions (Table 2).

Table 2. The frequency of recurrent abortions between HHV-6 DNA detected and HHV-6 DNA non-detected in both abortion and control groups

\begin{tabular}{cccc}
\hline Recurrent Abortions & Yes & No & Total \\
\hline HHV-6 DNA Detected & 3 & 16 & 19 \\
& $15.79 \%$ & $84.21 \%$ & $100 \%$ \\
HHV-6 DNA Non-detected & 4 & 67 & 71 \\
& $5.63 \%$ & $94.37 \%$ & $100 \%$ \\
\hline
\end{tabular}

Chi square $p$ value $=0.14$

In the abortion group only, this study also showed a higher frequency of recurrent abortions in HHV-6 DNA detected group than HHV-6 DNA non-detected group but it did not reach the statistical significance level this study showed non-significant differences ( $P$ value $=0.1$ ). It showed $33.33 \%$ of HHV-6 DNA detected with recurrent abortions, and only $11.11 \%$ of HHV-6 DNA non-detected group with recurrent abortions (Table 3).

Table 3. The frequency of recurrent abortions between HHV-6 DNA detected and HHV-6 DNA non-detected in abortion group

\begin{tabular}{cccc}
\hline Recurrent Abortions & Yes & No & Total \\
\hline HHV-6 DNA Detected & 3 & 6 & 9 \\
& $33.33 \%$ & $66.67 \%$ & $100 \%$ \\
HHV-6 DNA Non-detected & 4 & 32 & 36 \\
& $11.11 \%$ & $88.89 \%$ & $100 \%$ \\
\hline
\end{tabular}

Chi square $p$ value $=0.1$

On the other hand, the comparison of HHV-6 DNA load in HHV6-DNA positive only subjects in both abortion and control groups in regard to presence or absence of recurrent abortion history showed significant differences in the median of HHV-6 DNA between recurrent abortion and no recurrent abortion groups ( $P$ value $=0.033$ ). The median of HHV-6 DNA load in women with recurrent abortion was 36 copy no. $/ 10^{6}$ cells, and 13 copy no. $/ 10^{6}$ cells in nonrecurrent abortion (Table 4). 
Iraqi JMS 2019; Vol. 17(1)

Table 4. Comparison of HHV-6 DNA load in uterus lining tissue regard to recurrent abortion history

\begin{tabular}{ccc}
\hline Recurrent Abortions & Yes & No \\
\hline Median (Copy no. $/ 10^{6}$ cells) & 36 & 13 \\
Standard Deviation & 20.43 & 1946.9 \\
\hline \multicolumn{2}{c}{ Mann Whitney, P=0.033 (Significant) } \\
\hline
\end{tabular}

The positive/negative results of the anti-HHV-6 IgM serum antibodies in both abortion and control groups subjects with detected HHV-6 DNA versus non-detected HHV-6 DNA showed (0\%) of HHV-6 DNA detected were with positive IgM index versus up to (10\%) in HHV-6 DNA non- detected group but it did not reach the statistical significant $(P$ value $=0.33)$. The odds ratio 4.53 refers that the odds of PCR to detect HHV- 6 DNA in the lining tissue of uterus is 4.5 when IgM-HHV-6 is negative (Table 5).

Table 5. The positive/negative results of the anti-HHV-6 IgM serum antibodies in both abortion and control groups subjects with detected HHV-6 DNA versus non-detected HHV-6 DNA

\begin{tabular}{cccc}
\hline & $\begin{array}{c}\text { Negative IgM } \\
\text { Index }\end{array}$ & $\begin{array}{c}\text { Positive IgM } \\
\text { Index }\end{array}$ & Total \\
\hline HHV-6 DNA Detected & 19 & 0 & 19 \\
HHV-6 DNA Non-detected & $100 \%$ & $0 \%$ & $100 \%$ \\
& 64 & 7 & 71 \\
\hline
\end{tabular}

Fisher exact, $\mathrm{P}=0.33$, Odds ratio $=4.53, \mathrm{P}=0.32$

The positive/negative results of the anti-HHV-6 IgG serum antibodies in both abortion and control group subjects between detected HHV6 DNA versus non-detected HHV-6 DNA groups showed (100\%) of HHV-6 DNA detected subjects were positive, while (83\%) of HHV-6 DNA nondetected were positive with borderline statistical significance $(P$ value $=0.057)$. The odds ratio 8.2 that mean the odds for PCR to detect HHV-6 is 8 when IgG-HHV-6 is positive (Table 6).
The combination of positive/negative results of the anti-HHV-6 IgG and IgM serum antibodies in both abortion and control group subjects with detected HHV-6 DNA versus non-detected showed significant association between serology of HHV- 6 antibodies and the presence of HHV-6 DNA in uterus tissue (Fisher exact, $P$ value $=0.038$ ). It was shown $100 \%$ of HHV-6 DNA detected subjects were positive for IgG and negative for IgM versus $73 \%$ of non-detected subjects (Figure 1). 
Table 6. The positive/negative results of the anti-HHV-6 IgG serum antibodies in both abortion and control groups subjects with detected HHV-6 DNA versus non-detected HHV-6 DNA

\begin{tabular}{cccc}
\hline & $\begin{array}{c}\text { IgG Index } \\
\text { Positive }\end{array}$ & $\begin{array}{c}\text { IgG Index } \\
\text { Negative }\end{array}$ & Total \\
\hline HHV-6 DNA Detected & 19 & 0 & 19 \\
& $100 \%$ & $0 \%$ & $100 \%$ \\
HHV-6 DNA Non-detected & 59 & 12 & 71 \\
& $83.1 \%$ & $16.9 \%$ & $100 \%$ \\
\hline
\end{tabular}

Fisher exact, $\mathrm{P}=0.057$, Odds ratio $=8.2, \mathrm{P}=0.15$

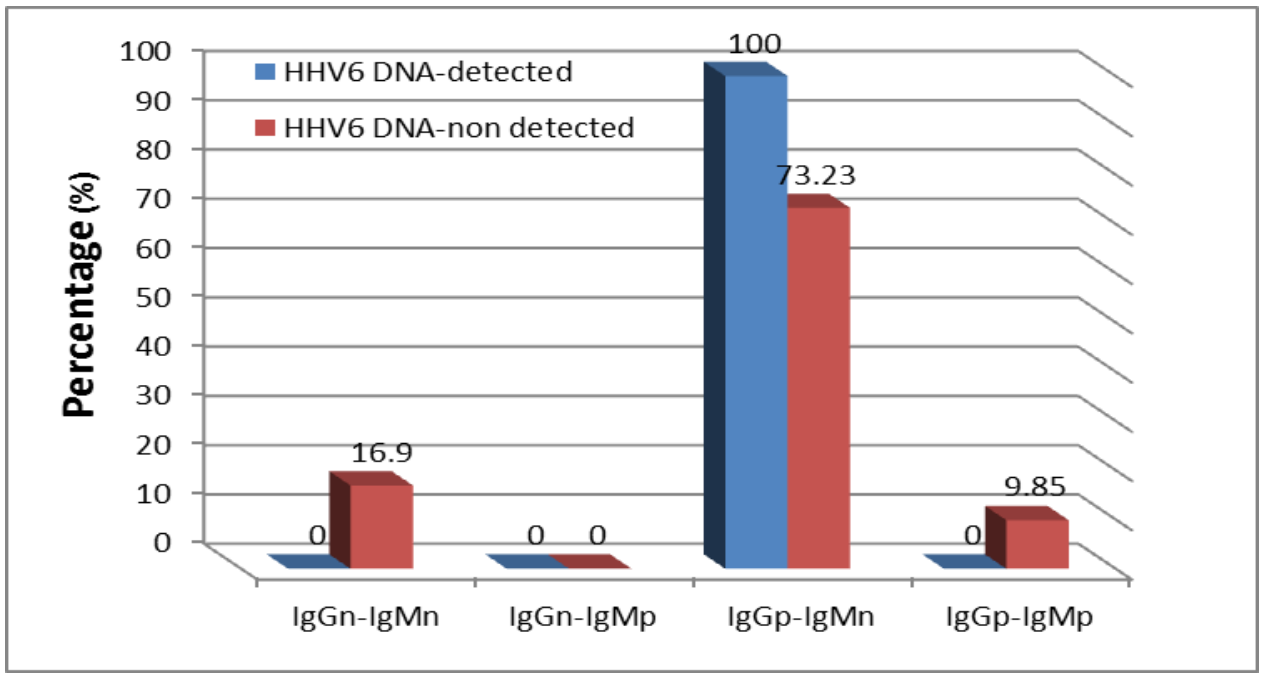

Figure 1. The combination of positive/negative results of the anti-HHV-6 IgG and IgM serum antibodies in both abortion and control group subjects with detected HHV-6 DNA versus nondetected HHV-6 DNA, a: IgGn-IgMn: both serum IgM and IgG are negative, b: IgGn-IgMp: serum IgG is negative and IgM is positive, c: IgGp-IgMn: serum IgG is positive and IgM is negative, d:

IgGp-IgMp: both serum IgM and IgG are positive

\section{Discussion}

Miscarriage and infertility are prevalent around the world and in many cases, the causes are unknown. HHV-6 (particular HHV-6A) is an etiological agent or a risk factor in a portion of these cases ${ }^{(7,11,12)}$.

In this study, HHV-6 DNA positivity was detected in $20 \%$ of miscarriage endometrial tissue while the uterus lining tissue of control group showed HHV-6 DNA in $22.22 \%$. There was no significant difference in the detection of the virus between both groups. Previous reports showed that HHV-6 DNA has been detected in genital tract secretions from pregnant and non-pregnant women ${ }^{(4,5)}$; HHV-6 DNA and antigens have been identified in biopsies of archived cervical samples ${ }^{(15,16)}$, and these suggest that the female genital tract may be the secondary site for HHV6 persistence.

The effect of virus on the pregnancy outcome related with other factors such as hormonal effect (12), immunological statues of individual $(12,17,18)$ that lead to reactivate of virus, and inhibit the creation of appropriate uterine environment for implantation and fetal growth that lead to miscarriage (11).

However, the history of previous abortions and recurrent abortions showed non-significant effect on HHV-6 DNA detection rate; it may be due to low samples size; this disagrees with the 
results of previous study that showed recurrent abortion due to maternal infections transmissible in utero at various stage of gestation can be caused by a wide array of organisms including HHV-6 ${ }^{(19)}$.

The viral load of HHV- $6 / 10^{6}$ cells of uterus lining tissue in positively detected cases was approximately 14.5 HHV-6 per $10^{6}$; the low viral load could be attributed to low samples size because one of abortion cases showed viral load equal 336100 virion $/ 10^{6}$ cells. In addition, the viral load of HHV-6/106 cells of uterus lining tissue showed non-significant differences between abortion and control groups. This disagrees with the results of previous research carried out recently in Italy on females with primary unexplained infertility in which viral load in endometrial tissue was shown to be 4 copies of HHV-6A per one diploid cell ${ }^{(12)}$. This stark difference in level of HHV-6 load in our study compared to that previous study may be attributed to less association of virus with miscarriage than female infertility. It could also be due to variations in environmental factors, estrogen levels, and immunological status between the population of the two studies effecting viral behavior.

The viral load significantly increased with the presence of recurrent abortion status ( $P$ value $=0.033$ ), this supports the notion that HHV-6 may be associated with unexplained recurrent abortion; and this agrees with the findings of a couple of previous studies that showed recurrent abortion due to maternal infections transmissible in utero at various stage of gestation can be caused by a wide array of organisms include HHV-6 (19,20), the clinical importance of this finding warrants further investigation.

Enzyme linked immune sorbent assay test for measurement HHV-6 IgM showed only $6.67 \%$ positive from abortion group, and $8.89 \%$ of control group was positive with non-significant differences; immunosuppression during pregnancy could be a possible reason for low percentage in both groups ${ }^{(21)}$.

This result agrees with results of previous studies on women who developed pityriasis rosea, which associated with the reactivation of HHV -6 and 7 during first trimester of pregnancy leading to high rate of abortion that showed HHV-6 IgM-negative for all samples ${ }^{(22,23)}$. This disagrees with the results of (Ando et al, 1992) who showed increased anti-HHV-6 IgM titer in abortion group (24); this is may be due to geographical differences as well as to variation in the type of infection, primary or reactivation of latent infection $(25,26)$.

All HHV-6 detected samples in abortion and control group was negative for anti HHV-6 IgM with odds ratio 4.53 , which means the odds are 4.53 for PCR to detect HHV-6 in uterus lining tissue when IgM-HHV-6 is negative; it may be due to immunosuppression status during pregnancy where more immunosuppression leads to more chances of HHV- 6 reactivation and lower titer or absence of HHV-6 $\operatorname{IgM}^{(21)}$, and reactivation of latent infection due to various factors including hormonal effect ${ }^{(12)}$ that more related with elevation of IgG antibodies ${ }^{(26)}$ than IgM antibodies that related with primary infection ${ }^{(25)}$. This result agrees with the result of previous studies on women with pityriasis rosea, who were associated with the reactivation of HHV-6 and 7 during first trimester of pregnancy leading to high rate of abortion; they showed that HHV-6 IgMnegative for all women with positive PCR for HHV-6 ${ }^{(22,23)}$.

The results of ELISA test detection anti HHV-6$\lg G$ antibody supporting this idea that showed all HHV-6 detected samples in abortion and control group was positive for anti HHV-6-IgG with odds ratio 8.2 that mean PCR turns out positive for HHV-6 when IgG-HHV-6 is positive by ELISA.

Also, $100 \%$ of HHV-6 DNA detected samples were positive for IgG and negative for IgM serum anti-HHV-6 antibodies with significant differences. This finding supports the above explanation that HHV-6 reactivate in uterus with immune suppression where IgM is missing and IgG is elevated.

The results of ELISA test for HHV-6 IgG showed 91.11\% positive from abortion group, and $82.22 \%$ of control group was positive with nonsignificant differences between both groups. It showed high value of IgG index may be due to same reason of above (reactivation of latent infection due to various factors including 
hormonal effect ${ }^{(12)}$ that related with elevation of IgG antibodies ${ }^{(26)}$ ).

More studies are needed to confirm the results of this study, further research to confirm whether HHV-6, in particular $\mathrm{HH}-6 \mathrm{~A}$, is an etiological agent or risk factor associated with unexplained miscarriage, and using of accurate treatment may make possible to carry healthy babies for more women.

This study concluded HHV-6 might be associated with unexplained miscarriage. The rate of HHV6 infection might increase with higher number of previous abortions, and with the presence of recurrent abortion history. Moreover, serum anti-HHV-6 IgM and IgG antibodies by ELISA might be a useful diagnostic method for detection of HHV- 6 infection in uterus lining tissue. The rate of HHV-6 infection in uterus lining tissue was higher when serum IgG positive and IgM negative.

\section{Acknowledgments}

To the staff members of Gynecology department in Al-Imamein Al-Kadhimein Medical City for their helping in samples collection.

\section{Author contribution}

All authors contributed to this manuscript. Dr. Abdulamir: design, interpreted and arranged this manuscript. Dosh: performed all the laboratory work, implementation and progress of this study. Dr. Abdul-Razzaq: help in clinical aspect and samples collection.

\section{Conflict of interest}

There is conflict of interest.

\section{Funding}

There is no funding.

\section{References}

1. Sultanova A. Significance of Beta-herpesviruses (HHV6, HHV-7) infection under the conditions of immune disorders. Doctoral Thesis 2014. Virology, Rigas Stradina University, Latvia.

2. Ablashi $D$, Agut $H$, Alvarez LR, et al. Classification of HHV-6A and HHV6-B as distinct viruses. Arch Virol. 2014; 159(5): 863-70. doi: 10.1007/s00705-013-19025.

3. Ahlqvist J, Fotheringham J, Akhyani $\mathrm{N}$, et al. Differential tropism of human herpesvirus-6 (HHV-6) variants and induction of latency by HHV-6A in oligodendrocytes. J Neuro virol. 2005; 11: 384-94. doi: 10.1080/13550280591002379.

4. Ohashi M, Yoshikawa T, Ihira M, et al. Reactivation of human herpesvirus- 6 and 7 in pregnant women. J Med Virol. 2002; 67(3): 354-8.

5. Baillargeon J, Piper J, Leach CT. Epidemiology of human herpesvirus-6 (HHV-6) infection in pregnant and non-pregnant women. J Clin Virol. 2000; 16(3): 149-57.

6. Leach CT, Newton ER, Mc Parlin S, et al. Human herpesvirus- 6 infection of the female genital tract. J Infect Dis. 1994; 169(1): 1281-3.

7. Revest M, Minjolle S, Veyer D, et al. Detection of HHV6 in over a thousand samples: new types of infection revealed by an analysis of positive results. J Clin Virol. 2011; 51(1): 20-4. doi: 10.1016/j.jcv.2011.02.001.

8. Giakoumelou S, Wheelhouse N, Cuschieri K, et al. The role of infection in miscarriage. Hum Reprod Update. 2016; 22(1): 116-33. doi: 10.1093/humupd/dmv041.

9. Rock JA, Zacur HA. The clinical management of repeated early pregnancy wastage. Fertil Steril. 1983; 39(2): 123-40.

10. Khameneh, ZR, Hanifian $H$, Barzegari R, et al. Human parvovirus B19 in Iranian pregnant women: a serologic survey. Indian J Pathol Microbiol. 2014; 57(3): 442-4. doi: 10.4103/0377-4929.138748.

11. Eliassen E, Marci R, Luca DD, et al. The use of heparin in infertility and recurrent pregnancy loss: Are its antiviral properties at play? J Medical Hypotheses. 2017; 102: 41-7. doi: 10.1016/j.mehy.2017.03.009.

12. Marci R, Gentili V, Bortolotti D, et al. Presence of HHV$6 \mathrm{~A}$ in endometrial epithelial cells from women with primary unexplained infertility. PLoS One 2016; 11(7): e0158304. doi: 10.1371/journal.pone.0158304.

13. Adams O, Krempe C, Kogler G, et al. Congenital infections with human herpesvirus-6. J Infect Dis. 1998; 178(2): 544-6.

14. Aubin, JT, Poirel L, Agut $H$, et al. Intrauterine transmission of human herpesvirus -6. Lancet. 1992; 340(8817): 482-3.

15. Wang $H$, Chen $M$, Berneman $Z N$, et al. Detection of human herpesvirus- 6 in paraffin-embedded tissue of cervical cancer by polymerase chain reaction. J Virol Methods. 1994; 47: 297-305. doi: 10.1016/01660934(94)90026-4.

16. Yadav M, Arivananthan M, Kumar S. HHV-6 antigen and viral DNA detected in cervical cells from archived tissue using histochemical staining and hybridization. Clin Diagn Virol. 1996; 7:23-33.

17. Seshadri S, Sunkara SK. Natural killer cells in female infertility and recurrent miscarriage: a systemic review and meta-analysis. Hum Reprod Update. 2014; 20(3): 429-38. doi: 10.1093/humupd/ dmt056.

18. Ozkan ZS, Deveci D, Kumbak B, et al. What is the impact of Th1/Th2 ratio, SOCS3, IL17, and IL35 levels in unexplained infertility? J Reprod Immunol. 2014; 103: 53-8. doi: 10.1016/j.jri.2013.11.002.

19. Nigro G, Mazzocco M, Mattia E, et al. Role of infections in recurrent spontaneous abortion. J Matern Fetal 
Neonatal Med. 2011; 24(8): 983-9. doi: 10.3109/14767058.2010.547963.

20. Haider M, Rizvi M, Khan N, et al. Serological study of herpes virus infection in female patients with bad obstetric history. Biol Med. 2011 3; 2: 284-90.

21. Dahl H, Fjaertoft $G$, Norsted $T$, et al. Reactivation of human herpesvirus-6 during pregnancy. J Infec Dis. 1999; 180: 2035-8. doi: 10.1086/315115.

22. Drago F, Broccolo F, Zaccaria E, et al. Pregnancy outcome in patients with pityriasis rosea. J Am Acad Dermatol. 2008; $58(5$ suppl 1): 78-83. doi: 10.1016/j.jaad.2007.05.030.

23. Drago $F$, Broccolo $F$, Javor $S$, et al. Evidence of human herpsvirus -6 and -7 reactivation in miscarrying women with pityriasis rosea. J Am Acad Dermatol. 2014; 71(1): 198-9. doi: 10.1016/j.jaad.2014.02.023.

24. Ando $Y$, Kaufman $K$, Ekuni $Y$, et al. HHV-6 infection during pregnancy and spontaneous abortion. Lancet. 1992; 340(8830): 1289.
25. Fox JD, Ward $P$, Briggs $M$, et al. Production of IgM antibody to HHV-6 in reactivation and primary infection. Epidemiol Infect. 1990; 104(2): 289-96.

26. Ihira M, Yoshikawa T, Suzuki K, et al. Correlation between human herpesvirus 6 and 7 infections after living related liver transplantation. Microbiol Immunol 2001; 45(3): 225-32. doi: https://doi.org/10.1111/j.1348-0421.2001.tb02611.x.

Correspondence to Huda S. Dosh

E-mail: hudadosh1992@yahoo.com

Received Oct. $21^{\text {st }} 2018$

Accepted Dec. $23^{\text {rd }} 2018$ 